\title{
The involvement of BDNF, NGF and GDNF in aging and Alzheimer's disease
}

\author{
Josiane Budni*, Tatiani Bellettini-Santos, Francielle Mina, Michelle Lima Garcez, Alexandra \\ Ioppi Zugno
}

Laboratório de Neurociências, Programa de Pós-Graduação em Ciências da Saúde, Unidade Acadêmica de Ciências da Saúde, Universidade do Extremo Sul Catarinense, Criciúma, SC, Brazil.

[Received June 11, 2015; Revised August 10, 2015; Accepted August 25, 2015]

\begin{abstract}
Aging is a normal physiological process accompanied by cognitive decline. This aging process has been the primary risk factor for development of aging-related diseases such as Alzheimer's disease (AD). Cognitive deficit is related to alterations of neurotrophic factors level such as brain-derived neurotrophic factor (BDNF), nerve growth factor (NGF) and glial cellderived neurotrophic factor (GDNF). These strong relationship between aging and AD is important to investigate the time which they overlap, as well as, the pathophysiological mechanism in each event. Considering that aging and $\mathrm{AD}$ are related to cognitive impairment, here we discuss the involving these neurotrophic factors in the aging process and AD.
\end{abstract}

Key words: BNDF, NGF, GDNF, Aging, Alzheimer's disease

The population is aging, since older individuals (those over 65 years of age) will double between 2000 and 2050 [1]. Aging is a natural physiological process, a progressive deterioration of the overall homeostatic brain mechanisms, accompanied by cognitive decline. A consequence of normal aging is a greater susceptibility to learning and memory impairments generally attributed to a decrease in neuronal plasticity of the cortex and hippocampus. Cognitive processes mediated by hippocampus and prefrontal cortex are most vulnerable to aging process [2]. Both brain regions suffer cellular and synaptic changes during aging that can be directly related to decline of cognitive performance [3].

Considering that the life expectancy of the population has increased, the senescence has been the primary risk factor for development of aging-related diseases such as Alzheimer's disease (AD) [4]. Cognitive deficits are the most common consequences of aging process and $\mathrm{AD}$ [4$6]$. $\mathrm{AD}$ is one of the most common and devastating agingrelated neurodegenerative diseases. This illness is characterized by massive neuronal loss, cognitive dysfunction and loss of memory. The incidence and prevalence continuously increases with advancing age. The clinical manifestation of disease occurs usually after the age of 65 [7].

Both aging process and $\mathrm{AD}$ are characterized by a progressive deterioration of learning and memory [4-6]. This strong relationship between aging and $\mathrm{AD}$ is important to investigate the time which they overlap, as well as, the pathophysiological mechanism in each event such as the involvement of the neurotrophic factors in these processes.

Neurotrophic factors are secreted protein that display important role in the synaptic and neuronal growth,

*Correspondence should be addressed to: Dr. Josiane Budni, Programa de Pós-Graduação em Ciências da Saúde, 
pruning, myelination, differentiation, and survival of neuronal $[8,9]$. There are three neurotrophic factors that will be addressed in the review: brain-derived neurotrophic factor (BDNF), nerve growth factor (NGF) and glial cell-derived neurotrophic factor (GDNF). These neurotrophic factors signaling are also severely affected in aging process and $\mathrm{AD}$ which can be correlated with cognitive decline.
Despite the fact that age-related and AD cognitive deficits are well-documented, the underlying BDNF, NGF and GDNF changes in the brain remain largely unclear. Therefore, this review discusses the involving of these neurotrophic factors in the aging process and agingrelated diseases such as $\mathrm{AD}$.

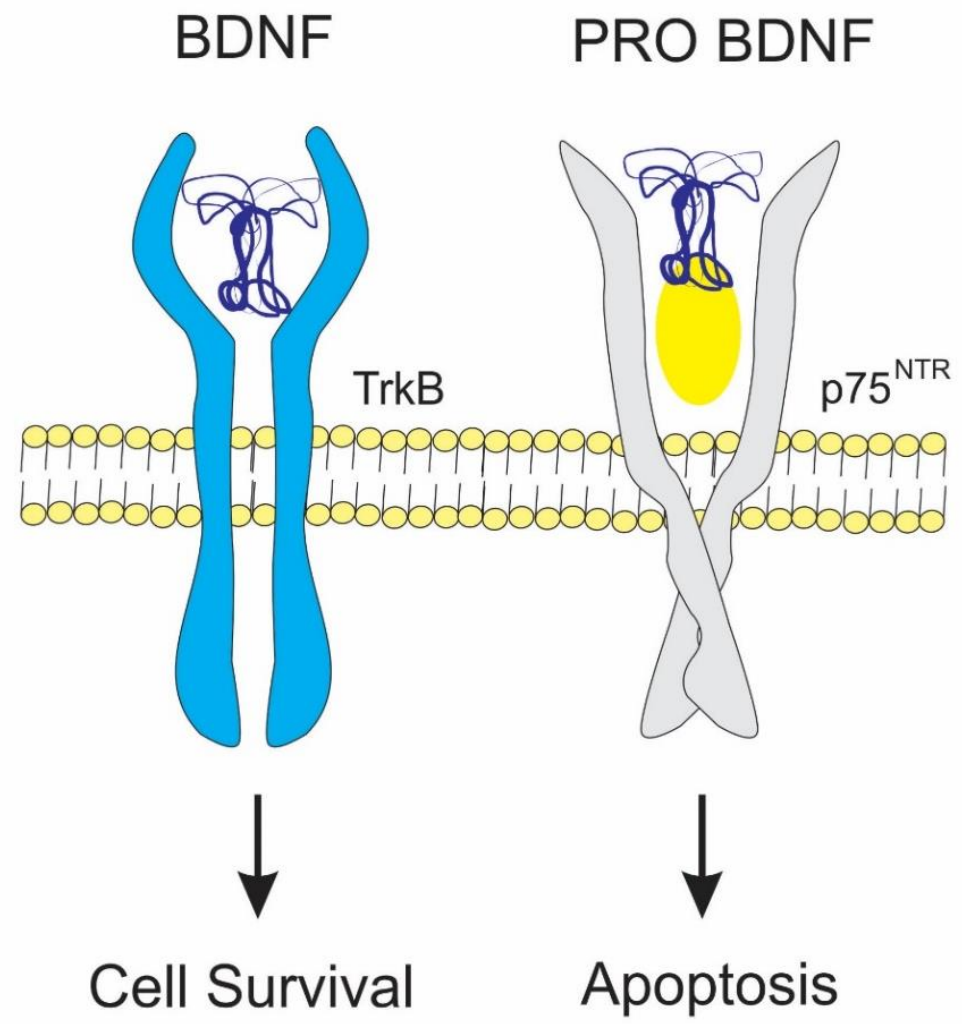

Figure 1. BDNF or pro-BDNF receptor. The BDNF binds to TrkB receptor and this interaction induces the activation of pathway signaling to culminate in cell survival. When the pro-BDNF binds $\mathrm{p} 75^{\mathrm{NTR}}$ can lead to apoptosis. Abbreviations: BDNF, brain-derived neurotrophic factor; p75 ${ }^{\mathrm{NTR}}$, p75 neurotrophin receptor.

\section{BDNF and aging}

BDNF is differentially expressed across several brain tissues. Nutrition, metabolism, behaviour, and stress affected the expression this neurotrophic factor in the central and peripheral nervous systems [10]. BDNF is synthesized from BDNF pro-isoform, which is then cleaved proteolytically ( $\mathrm{N}$-terminal domain is removed) inside the neuron or after it is released, creating its final protein form [11]. This mature neurotrophin binds to protein-kinase neurotrophin receptors - tropomyosinerelated kinase (Trk) receptors. BDNF is crucial to learning and memory, since it regulates LTD (long-term depression) and LTP (long-term potentiation), synaptic plasticity, axonal sprouting, proliferation of dendritic arbor, and neuronal differentiation $[12,13]$. These 
mechanisms in the central nervous system are activated through BDNF interaction with Trk B receptors [14]. The pro-BDNF binds to the $\mathrm{p} 75$ neurotrophin receptor (p75NTR) [15]. In contrast, when the pro-BDNF binds to p75NTR activates apoptotic pathways in peripheral neurons and glia [16] (Figure 1).

BDNF is capable of modulating diverse biological processes such as aging via interaction with different receptors [17].

In the aging occurs gradual impairment of cognitive abilities which are associated with cortical or hippocampal alterations, two brain regions involved in memory and learning processes [18]. BDNF helps to protect neurons from damage caused by infection or injury. It is a small dimeric protein, structurally related to NGF, which is abundantly and widely expressed in the adult mammalian brain [12, 19] acting also as an important mediator of synaptic plasticity and memory formation [20]. BDNF expression in the central nervous system is modified by many brain insult, such as seizure, stress, ischemia, and hypoglycemia [21, 22]. Alterations in its expression may contribute to some pathologies such as depression, AD, Parkinson's disease and epilepsy [22].

A study involving human adults aged 20-93 years [23], investigated the effects of BDNF polymorphism on multiple indices of memory (prospective, associative, subjective complaints and item). Results suggested that a genetic predisposition to BDNF val66met polymorphism, exerts influence on multiple indices of episodic memory. In some cases, this polymorphism can be alter the subjective memory and perhaps associative memory [24]. Another study performed with men and women of Finnish origin, suggested that BDNF was not associated with cognition in men. However, BDNF level can indicate the impaired memory and general cognitive function in aging women [25].

A preclinical study showed that a chronic BDNF deficiency leads learning deficit dependent on age in animals after seven months. These authors also observed a positive correlation between hippocampus BDNF levels and learning performance during the probe trial involving animals that showed a good learning performance during the long-term memory test [26].

A study in nerve cells from rats reported that $\gamma$ secretase inhibitors (GSIs) disrupted the retrograde axonal trafficking of BDNF, suppressed BDNF-induced downstream signalling pathways and induced changes in the distribution of neuronal processes in mitochondria and synaptic vesicles. In contrast, treatment with a novel class of $\gamma$-secretase modulators (GSMs) had no significant effect, since knockdown of APP by specific siRNA prevented GSI-induced changes in BDNF axonal trafficking and signalling. It was also reported that GSI effects on APP processing were responsible, at least in part, for BDNF trafficking and signalling deficits [27]. Moreover, a study performed in rats showed that TrkB receptors are markedly decreased in the pituitary during the aging process. It also reported that a possible trophic role of BDNF in the pituitary might be significantly reduced. This can be a result of the decrease in TrkB receptors during aging, since BDNF may be an intercellular messenger to help regulate some pituitary functions. A decrease in BDNF receptors rather than in BDNF itself might contribute to endocrine alterations associated with aging [28].

It was also reported that the administration of exogenous BDNF produced a marked increase in the multi-threshold locus coeruleus (LC), accompanied with a decrease in threshold current. Besides, no morphological changes to the noradrenergic axons were observed in the BDNF-infused cortex [29]. The infusion of anti-BDNF led to a dose-dependent reduction of the multi-threshold LC neurons, accompanied with an increase in threshold current. The results of this study also suggest that BDNF may contribute to functional changes in the pre-synaptic axon terminals of LC neurons in the aging brain [29]. Furthermore, BDNF is necessary for the maintenance of noradrenergic innervations in the aged brain [30]. Therefore, BDNF display an important role in aging process.

\section{BDNF and Alzheimer's disease}

Studies have demonstrated the role of BDNF in both animal models, and patients with AD. BDNF is important in neuronal growth and neuronal survival, participating in the synaptic processes of memory. Evidence has suggested the involvement of BDNF with AD pathology. Studies have shown alterations in the levels of this neurotrophin in AD patients. Results show reduction (21$30 \%$ ) in pro-BDNF in patients with MCI (mild cognitive impairment) and major reduction $(40 \%)$ in terminal patients. These results suggest the involvement of BDNF with cognitive dysfunction in AD patients [31]. Another studies have shown BDNF levels diminished in AD patients as compared to controls [32-37]. Lee (2009) also observed a BDNF levels decrease in both AD and MCI patients [38]. Other results showed increase in the BDNF levels in these patients. Authors suggest that this increase may be an upregulation of BDNF [39, 40]. Reductions in the levels of BDNF, NGF and GDNF were observed in 26 patients with moderate $\mathrm{AD}$ and 62 with MCI [41]. Changes in BDNF levels are well related to cognitive impairment. Studies analyzing frontotemporal dementia (FTD), Lewy body dementia (LBD), vascular dementia (VAD) and AD found a decrease in BDNF levels, when compared to controls [42]. 


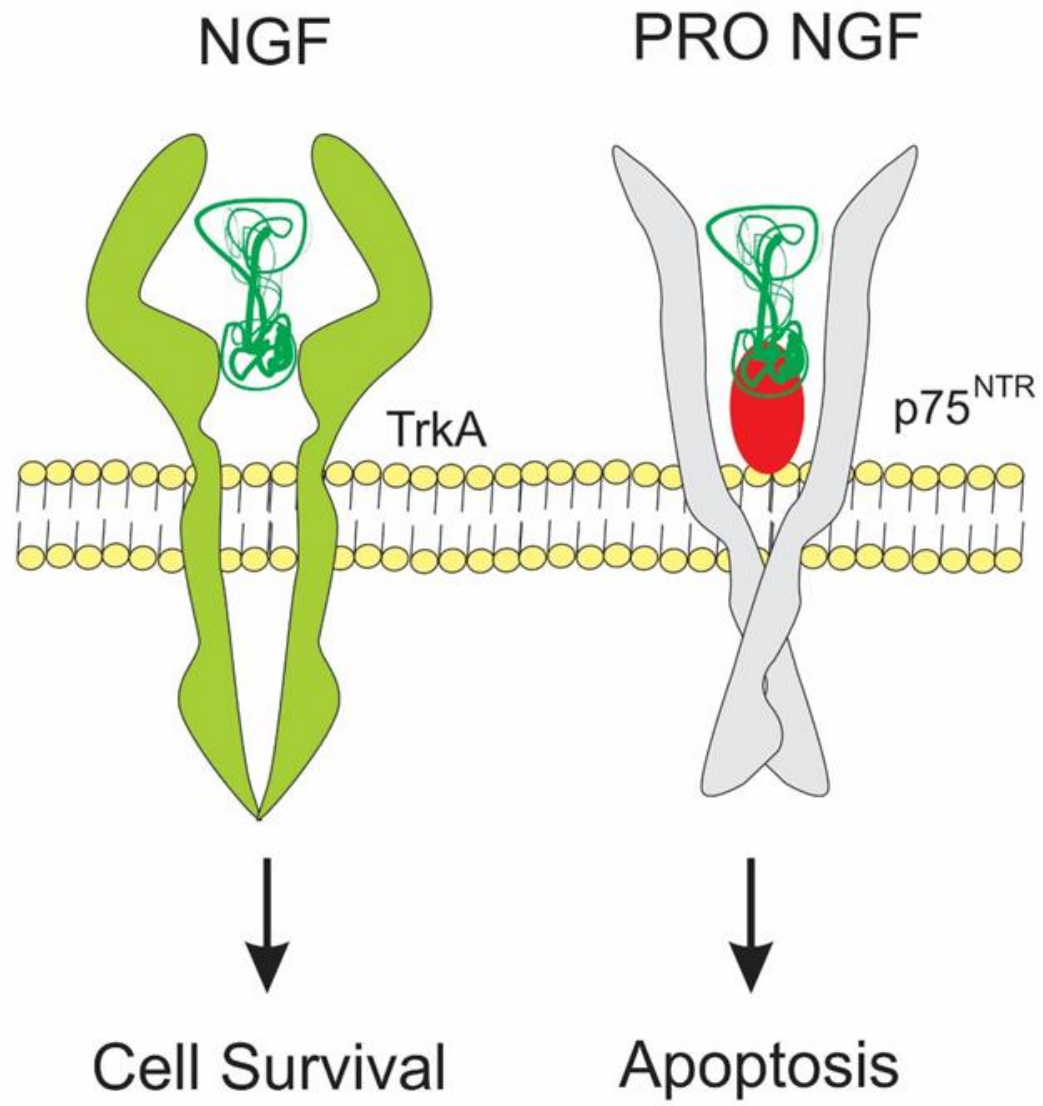

Figure 2. NGF or pro-NGF receptor. The NGF binds to TrkA receptor and this interaction induces the activation of pathway signaling to culminate in cell survival. When the pro-NGF binds p75 $5^{\mathrm{NTR}}$ can lead to apoptosis. Abbreviations: NGF, nerve growth factor; $\mathrm{p} 75^{\mathrm{NTR}}, \mathrm{p} 75$ neurotrophin receptor.

On the other hand, some results have shown increases in the levels of BDNF in AD patients when compared to controls and MCI [40]. Increased expression of TrкB was found in CA1 region of the hippocampus of patients in early stages of $\mathrm{AD}[43]$. Other results also demonstrated an increase in the levels of BDNF in both AD and MCI patients, not disease severity or acetylcholinesterase administration dependent [39]. Beyond BDNF, Glycogen synthase kinase-3 $\beta$ (GSK3 $\beta$ ) and cAMP-response element-binding protein (CREB) are signaling molecules that can be involved in the neurodegenerative progression $[44,45]$. A study showed that platelet GSK3 $\beta$ activity, lymphocyte CREB activity and plasma BDNF have been related to AD. Increased GSK3B and CREB activity was found in $\mathrm{AD}$ patients with depressive symptoms. This increase in CREB can be explained by the presence of depressive symptoms in these patients or because of low BDNF levels in patients suffering with depression [33]. These changes in the levels of BDNF may be well related to the several stages of AD pathology. Decreased levels have been observed in later stages and an increase in the initial stages, which may be a regulatory organism of memory loss. Another remarkable characteristic is the BDNF val66met polymorphism. However, some results shows that it is not associated with development of AD. In a sample of 149 patients, no relationship was found with genotype vall66met [46]. According another studies, there is no association between vall66met and BDNF changes in $\mathrm{AD}$ [47-50]. Further studies are required to understand the exact relationship between polymorphism 
and dysfunction to BDNF levels in AD. Population studies have shown to date, a small sample size and this may be a weakness for these studies.

Preclinical reports have investigated possible pharmacological treatments to increase BDNF levels in transgenic mice [51-53] or in animals subjected to administration of amyloid $\beta$ peptide. Treatments with caffeine in AD transgenic animals shows increased levels of BDNF, and chronic treatments with caffeine improved both BDNF levels and cognitive impairment. Pioglitazone, a hypoglycemiant drug, restores BDNF levels and attenuates the inflammatory markers in an animal model of $\mathrm{AD}$ induced by amyloid $\beta$ peptide administration. The oral administration of fingolimod improved both BDNF levels and cognitive impairment observed in animals $[54,55]$.

It is observed that additional research is needed to understand the relationship between BDNF and AD. A potential treatment with BDNF seems to be a possible therapeutic target for patients, perhaps improving cognitive dysfunction.

\section{NGF and aging}

NGF is a glycoprotein that consists of three sub-units: $\alpha$ NGF that is inactive; $\beta$-NGF that is biologically active and $\gamma$-NGF that processes the NGF precursor into its mature form. NGF is synthesized as a precursor from pro-NGF and is either secreted outside the cells or cleaved intracellularly into mature NGF. The secretion of NGF can be a mixture of pro-NGF and mature NGF. There are three types of NGF receptors, these being; TrkA, p75 and sortilin. The trophic effect of NGF is mediated through of TrkA and p75 receptors [56, 57], while the neurotoxic effect of pro-NGF is mediated through p75 in conjunction with sortilin [58] (Figure 2). Pro-NGF is the predominant form of NGF in central nervous system [59].

It has been related that increase proNGF levels induce apoptosis in various types of cells under seizures and spinal cord injury [60, 61]. Moreover, evidence indicate that pro-NGF inhibit the proliferation and differentiation of hippocampal neural stem or progenitor cells from postnatal mice [62]. These effects of pro-NGF might be mediated through p75NTR [63] (Figure 2). In this context, a study performed by Al-Shawi et al (2008) indicated that proNGF leads cell death in basal forebrain and peripheral sympathetic neurons of old rat. This effect not found in young animals. Moreover, pro-NGF was elevated during aging in the projection areas of some populations of vulnerable central and peripheral neurons [64]. Terry et al., (2011) showed age-related impairments in spatial learning and deficits in recognition memory. These effects were accompanied by elevated levels of the pro-NGF,
p75NTR and sortilin in the prefrontal cortex and hippocampus of aged rats [65].

Growth factors like NGF are important in the neuronal plasticity and survival of forebrain cholinergic neurons (cerebral cortex, hippocampus, basal forebrain and hypothalamus), which are memory-related [66]. [67] found decreased levels of NGF in the hippocampus of 28month-old Fischer rats, while [68] showed that NGF levels were decreased in the cortex of 24-month-old wistar rats. Considering that NGF is important for cognitive functions, and it was found to have decreased with aging, this neurotrophic factor might contribute to an age-dependent decline in cognitive function [67-69]. Therefore, it plays a significant role in memory and cognition, and the development, survival and maintenance of cholinergic neurons [70], usually in the aging brain.

\section{NGF and Alzheimer's disease}

Recent studies have shown that NGF plays a role in aging as well as in age-related diseases such as AD, since aging can interact with preexisting abnormalities in trophic signaling to trigger cholinergic and cognitive decline as observed in AD [71].

There are different evidences about NGF level in clinical and preclinical studies. For instant, [72] observed no differences of NGF levels in the in serum, brain-spinal fluid, and brain (hippocampus and parietal cortex) in AD patients. NGF levels in the dentate gyrus of AD patients were higher [40]. Also reported no significant differences in the plasma NGF levels of AD patients as compared to control group. In contrast, [73] found increase of NGF levels in cerebrospinal fluid of AD patients. [74] showed that the amyloid $\beta$ (25-35) administration intrececebroventricular for 14 days, in mouse, induced reduction of NGF protein expression, which might contribute to the cognitive impairments found in this animal model of AD.

An interesting study has shown the effects of NGF treatment on patients with $\mathrm{AD}$. Results showed that after treatment lasting for 12 months, patients had improvements in cognitive function, and lower levels of amyloid $\beta$ in their cerebrospinal fluid [75]. Increased proNGF was observed in post-mortem studies of patients with $\mathrm{AD}$ [76]. In another study, six AD patients were treated with NGF for 12 months. Results were positive, showing lower levels of amyloid $\beta$ in their cerebrospinal fluid. However, most patients showed signs of brain atrophy, as evidenced by increases in phosphorylated tau [77]. Reductions in NGF levels can be caused by decreased cholinergic activity, and the death of parts of the post frontal and temporal cortex, as seen in $\mathrm{AD}$ patients [78]. Side effects were also noted with NGF 
treatments. After three months of treatment, it was found that patients had back pain, which brought an interruption in the treatment. Despite the small sample numbers used in the study, the authors suggest that other alternative routes of administration or lower doses may minimize side effects [79].

Pre-clinical research has focused on NGF, seeking cognitive improvements and increased levels of neurotrophins. transgenic animals observed increases in the levels of NGF, BDNF, and NT3, and reductions in the number of hippocampal amyloid $\beta$ (1-40)- and amyloid $\beta$ (1-42) -positive amyloid plaques after the treatment with insulin-like growth factor 2 (IGF2) [80]. Already it has been found that treatment with valproate (VPA) in animals with $\mathrm{AD}$ decreased the nuclear factor kappa $\mathrm{B}$ (NFKB) of IL-1 $\beta$ mRNA. VPA has also increased NGF levels in the hippocampus of animals that were 5 and 10 months of age [81]. Moreover, it is important emphasize that amyloid $\beta$ blocks neuronal function via the inhibition of kinesin 5 , consequently reducing the transport of cellsurface NGF/NTR(p75) in PC 12 cells [82].

In contrast to NGF, increases in pro-NGF have been related to AD patients [83-85] and patients affected by MCI [83]. These studies indicated that NGF and pro-NGF might be an important target in $\mathrm{AD}$.

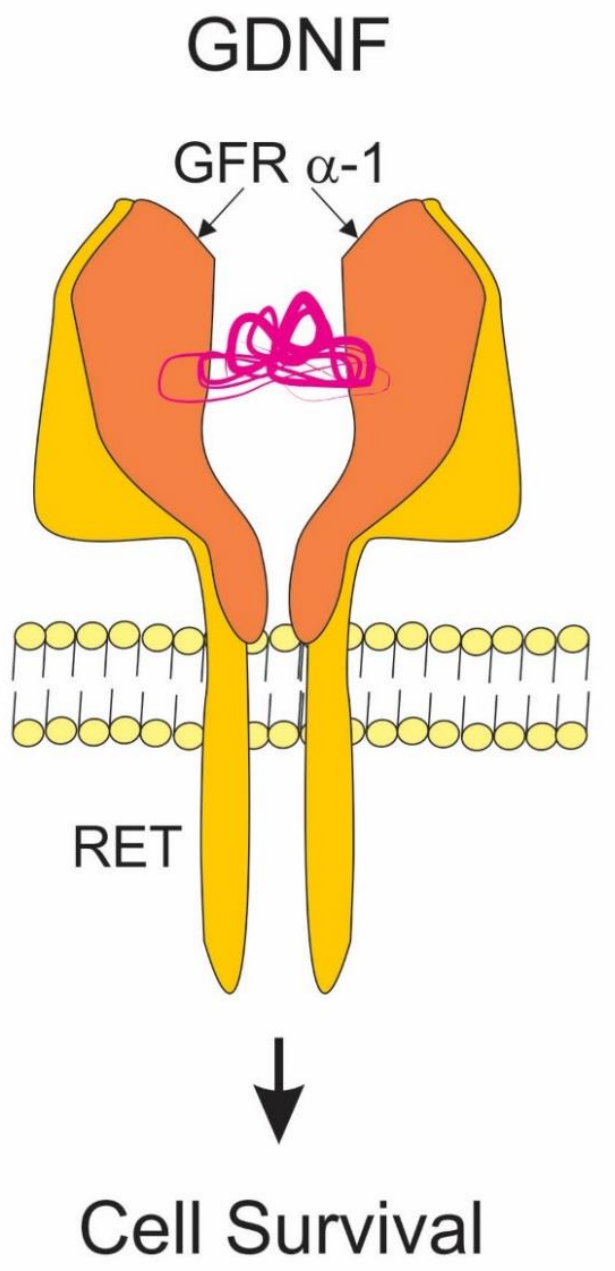

Figure 3. GDNF receptor. The GDNF binds to a multi-component receptor complex compound by GFR $\alpha 1$ and RET inducing cell survival. Abbreviations: GDNF, glial cell-derived neurotrophic factor; GFR $\alpha 1$, GDNF receptor alpha1; RET, signaling component rearranged during transfection. 


\section{GDNF and aging}

GDNF (originally isolated from the supernatant of a rat glioma cell-line) is an important growth factor for the development, survival, and maintenance of midbrain dopaminergic neurons [86, 87]. GDNF interacts to a multi-component receptor complex compound by ligand binding cell surface component GDNF receptor alpha1 (GFR $\alpha 1)$ and signaling component rearranged during transfection (RET) receptor tyrosine kinase [88, 89] (Figure 3).

It's known that motor function and all dopaminergic system have a decline with normal age and Parkinson's disease patients have an intense decline in this system [90]. The potential of GDNF against age-related cognitive deterioration has not been fully explored. [91], had assayed GDNF for its neurotrophic effects against the neuronal atrophy that causes cognitive deficits in old age, and they found that spatial learning and memory testing showed a significant gain in cognitive abilities due to GDNF exposure. However, the specificity of GDNF to dopaminergic area is the reason that it has been studied for potential use for the treatment of Pankinson's Disease, with clinical trials currently in progress. In this context, [92] has been studying GDNF administration as therapeutic option for neurodegeneration. It has been described that GDNF could exert neuroprotective and neurorestorative effects on substantia nigra neurons in animal models of Parkinson's Disease, as well as in patients $[93,94]$.

Other systems also seem to be related to GDNF. [95] suggest that reduced levels of GDNF induce excess glutamate release and deregulation of glutamate transporter-1, causing excitotoxicity in the nervous system that precedes dopaminergic degeneration. In this sense, a study performed by [96], showed GDNF expression level was increased with age in the frontal cortex, but was not in the hippocampus, in the agedependent changes in LC noradrenergic innervations suggesting that these innervations may be locally regulated by different neurotrophic factors that exert their trophic actions at different target sites.

It has also been found to have trophic and protective effects on noradrenergic neurons in the LC, as well as peripheral motor neurons [97-99]. It has already been shown to prevent both neurons and glial cells from oxidative stress $[100,101]$. [102] indicate that GDNF can protect nigrostriatal dopamine neurons against the effects of 6-hydroxydopamine in aged as well as young adult rats. Moreover, an additional study showed a significant increase of GDNF protein content in the spinal cord of old (24-month-old) rats subjected to 2 weeks of exercise [103].

\section{GDNF and Alzheimer's disease}

GDNF has been hardly studied and depletion of this neurotrophic factor seems to be linked with disease, pathology and symptoms such as $\mathrm{AD}$ [92]. A study performed by [104] showed that the GDNF administration can protect against AD-like chances induced by injection of aluminum complexes in rabbit.

Disturbances in cholinergic neurons may occur as a consequence of effects concerning catecholaminergic neurons and it can be related with AD. [105] found increased GDNF in cerebrospinal fluid and decreased serum concentration of GDNF in patients with $\mathrm{AD}$ in early stages suggesting an adaptive process of the impaired brain. [106] showed increased GDNF levels in plasma of AD patients. Moreover, in postmortem middle temporal gyrus of $\mathrm{AD}$ patients, [107] observed that mature GDNF peptide was down-regulated. In the same line, a study found the serum GDNF levels significantly reduced in MCI and AD patients [108]. In contrast, [40] observed no significant differences in the GDNF levels of plasma of $\mathrm{AD}$ patients and control group showed.

Recently, [109], have reported that GDNF was down regulated in 3xTgAD mice (a transgenic strain of mice) and 6 months of voluntary exercise was capable of reverse this effect. Furthermore, it has reported that 10-month-old $3 \times$ Tg-AD mice subjected to 6 months of overexpressing GDNF (recombinant lentiviral vectors), showed improvement in the learning and memory. This GDNF neuroprotective effect induced a potent upregulation of BDNF, indicating that together may important against neurons atrophy and degeneration [110].

\section{Conclusion}

The major risk factor for neurodegeneration and cognitive decline is the aging of the brain. The changes in neurotrophic factors expression are not well characterized during human brain development and aging. Knowing these changes may elucidate structural, metabolic, and functional brain processes over the lifespan, as well vulnerability to neurodevelopmental or neurodegenerative diseases.

\section{References}

[1] Guerin B, Hoorens S, Khodyakov D, Yaqub O (2015). A growing and ageing population.

[2] Barrientos RM, Kitt MM, Watkins LR, Maier SF (2015). Neuroinflammation in the normal aging hippocampus: Neuroscience.

[3] Morrison JH, Baxter MG (2012). The ageing cortical synapse: hallmarks and implications for cognitive decline. Nat Rev Neurosci, 13(4):240-50. 
[4] Bishop NA, Lu T, Yankner BA (2010). Neural mechanisms of ageing and cognitive decline. Nature, 464(7288):529-35.

[5] Baquer NZ, Taha A, Kumar P, McLean P, Cowsik SM, Kale RK, et al. (2009). A metabolic and functional overview of brain aging linked to neurological disorders. Biogerontology, 10(4):377-413.

[6] Samanez-Larkin GR, Knutson B (2015). Decision making in the ageing brain: changes in affective and motivational circuits. Nat Rev Neurosci, 16(5):278-89.

[7] Mufson EJ, Mahady L, Waters D, Counts SE, Perez SE, DeKosky ST, et al. (2015). Hippocampal plasticity during the progression of Alzheimer's disease. Neuroscience, 12(15):00221-3.

[8] Skaper SD (2012). The neurotrophin family of neurotrophic factors: an overview. Methods Mol Biol, 846:1-12.

[9] Huang EJ, Reichardt LF (2001). Neurotrophins: roles in neuronal development and function. Annu Rev Neurosci, 24:677-736.

[10] Fuchikami M, Morinobu S, Kurata A, Yamamoto S, Yamawaki S (2009). Single immobilization stress differentially alters the expression profile of transcripts of the brain-derived neurotrophic factor (BDNF) gene and histone acetylation at its promoters in the rat hippocampus. Int J Neuropsychopharmacol, 12(1):7382.

[11] Ahmed AO, Mantini AM, Fridberg DJ, Buckley PF (2015). Brain-derived neurotrophic factor (BDNF) and neurocognitive deficits in people with schizophrenia: A meta-analysis. Psychiatry Res, 226(1):1-13.

[12] Murer MG, Yan Q, Raisman-Vozari R (2001). Brainderived neurotrophic factor in the control human brain, and in Alzheimer's disease and Parkinson's disease. Prog Neurobiol, 63(1):71-124.

[13] Tyler WJ, Alonso M, Bramham CR, Pozzo-Miller LD (2002). From acquisition to consolidation: on the role of brain-derived neurotrophic factor signaling in hippocampal-dependent learning. Learn Mem, 9(5):22437.

[14] Islam O, Loo TX, Heese K (2009). Brain-derived neurotrophic factor (BDNF) has proliferative effects on neural stem cells through the truncated TRK-B receptor, MAP kinase, AKT, and STAT-3 signaling pathways. Curr Neurovasc Res, 6(1):42-53.

[15] Hibbert AP, Kramer BMR, Miller FD, Kaplan DR (2006). The localization, trafficking and retrograde transport of BDNF bound to p75NTR in sympathetic neurons. Mol Cell Neurosci, 32(4):387-402.

[16] Teng HK, Teng KK, Lee R, Wright S, Tevar S, Almeida $\mathrm{RD}$, et al. (2005). ProBDNF induces neuronal apoptosis via activation of a receptor complex of p75NTR and sortilin. J Neurosci, 25(22):5455-63.

[17] Silhol M, Arancibia S, Perrin D, Maurice T, Alliot J, Tapia-Arancibia L (2008). Effect of aging on brainderived neurotrophic factor, proBDNF, and their receptors in the hippocampus of Lou/C rats. Rejuvenation Res, 11(6):1031-40.

[18] Tapia-Arancibia L, Aliaga E, Silhol M, Arancibia S (2008). New insights into brain BDNF function in normal aging and Alzheimer disease. Brain Res Rev, 59(1):201-20.

[19] Patterson SL (2015). Immune dysregulation and cognitive vulnerability in the aging brain: Interactions of microglia, IL-1 $\beta$, BDNF and synaptic plasticity. Neuropharmacology, 96(Pt A):11-8.

[20] Cowansage KK, LeDoux JE, Monfils MH (2010). Brainderived neurotrophic factor: a dynamic gatekeeper of neural plasticity. Curr Mol Pharmacol, 3(1):12-29.

[21] Yan Q, Rosenfeld RD, Matheson CR, Hawkins N, Lopez OT, Bennett L, et al. (1997). Expression of brain-derived neurotrophic factor protein in the adult rat central nervous system. Neuroscience, 78(2):431-48.

[22] Tapia-Arancibia L, Rage F, Givalois L, Arancibia S (2004). Physiology of BDNF: focus on hypothalamic function. Front Neuroendocrinol, 25(2):77-107.

[23] Kennedy KM, Reese ED, Horn MM, Sizemore AN, Unni AK, Meerbrey ME, et al. (2015). BDNF val66met polymorphism affects aging of multiple types of memory. Brain Res, 1612:104-17.

[24] Tong CW, Wang ZL, Li P, Zhu H, Chen CY, Hua TM (2015). Effects of senescence on the expression of BDNF and TrkB receptor in the lateral geniculate nucleus of cats. Dongwuxue Yanjiu, 36(1):48-53.

[25] Komulainen P, Pedersen M, Hänninen T, Bruunsgaard H, Lakka TA, Kivipelto M, et al. (2008). BDNF is a novel marker of cognitive function in ageing women: The DR's EXTRA Study. Neurobiol Learn Mem, 90(4):596603.

[26] Petzold A, Psotta L, Brigadski T, Endres T, Lessmann V (2015). Chronic BDNF deficiency leads to an agedependent impairment in spatial learning. Neurobiol Learn Mem, 120:52-60.

[27] Weissmiller AM, Natera-Naranjo O, Reyna SM, Pearn ML, Zhao X, Nguyen P, et al. (2015). A gamma-Secretase Inhibitor, but Not a gamma-Secretase Modulator, Induced Defects in BDNF Axonal Trafficking and Signaling: Evidence for a Role for APP. PLoS One, 10(2):e0118379.

[28] Rage F, Silhol M, Binamé F, Arancibia S, Tapia-Arancibia $\mathrm{L}$ (2007). Effect of aging on the expression of BDNF and TrkB isoforms in rat pituitary. Neurobiol Aging, 28(7):1088-98.

[29] Nakai S, Matsunaga W, Ishida Y, Isobe K-i, Shirokawa T (2006). Effects of BDNF infusion on the axon terminals of locus coeruleus neurons of aging rats. Neurosci Res, 54(3):213-9.

[30] Matsunaga W, Shirokawa T, Isobe K (2004). BDNF is necessary for maintenance of noradrenergic innervations in the aged rat brain. Neurobiol Aging, 25(3):341-8.

[31] Peng S, Wuu J, Mufson EJ, Fahnestock M (2005). Precursor form of brain-derived neurotrophic factor and mature brain-derived neurotrophic factor are decreased in the pre-clinical stages of Alzheimer's disease. J Neurochem, 93(6):1412-21.

[32] Yasutake C, Kuroda K, Yanagawa T, Okamura T, Yoneda H (2006). Serum BDNF, TNF-alpha and IL-1beta levels in dementia patients: comparison between Alzheimer's disease and vascular dementia. Eur Arch Psychiatry Clin Neurosci, 256(7):402-6. 
[33] Platenik J, Fisar Z, Buchal R, Jirak R, Kitzlerova E, Zverova M, et al. (2014). GSK3beta, CREB, and BDNF in peripheral blood of patients with Alzheimer's disease and depression. Prog Neuropsychopharmacol Biol Psychiatry, 50:83-93.

[34] Laske C, Stransky E, Leyhe T, Eschweiler GW, Maetzler W, Wittorf A, et al. (2007). BDNF serum and CSF concentrations in Alzheimer's disease, normal pressure hydrocephalus and healthy controls. J Psychiatr Res, 41(5):387-94.

[35] Forlenza OV, Diniz BS, Teixeira AL, Ojopi EB, Talib LL, Mendonca VA, et al. (2010). Effect of brain-derived neurotrophic factor Val66Met polymorphism and serum levels on the progression of mild cognitive impairment. World J Biol Psychiatry, 11(6):774-80.

[36] Hock C, Heese K, Hulette C, Rosenberg C, Otten U (2000). Region-specific neurotrophin imbalances in Alzheimer disease: decreased levels of brain-derived neurotrophic factor and increased levels of nerve growth factor in hippocampus and cortical areas. Arch Neurol, 57(6):84651.

[37] Gezen-Ak D, Dursun E, Hanagasi H, Bilgic B, Lohman E, Araz OS, et al. (2013). BDNF, TNFalpha, HSP90, CFH, and IL-10 serum levels in patients with early or late onset Alzheimer's disease or mild cognitive impairment. J Alzheimers Dis, 37(1):185-95.

[38] Lee JG, Shin BS, You YS, Kim JE, Yoon SW, Jeon DW, et al. (2009). Decreased serum brain-derived neurotrophic factor levels in elderly korean with dementia. Psychiatry Investig, 6(4):299-305.

[39] Angelucci F, Spalletta G, di Iulio F, Ciaramella A, Salani F, Colantoni L, et al. (2010). Alzheimer's disease (AD) and Mild Cognitive Impairment (MCI) patients are characterized by increased BDNF serum levels. Curr Alzheimer Res, 7(1):15-20.

[40] Faria MC, Goncalves GS, Rocha NP, Moraes EN, Bicalho MA, Gualberto Cintra MT, et al. (2014). Increased plasma levels of BDNF and inflammatory markers in Alzheimer's disease. J Psychiatr Res, 53:166-72.

[41] Forlenza OV, Teixeira AL, Miranda AS, Barbosa IG, Talib LL, Diniz BS, et al. (2015). Decreased Neurotrophic Support is Associated with Cognitive Decline in NonDemented Subjects. J Alzheimers Dis.

[42] Ventriglia M, Zanardini R, Bonomini C, Zanetti O, Volpe D, Pasqualetti P, et al. (2013). Serum brainderived neurotrophic factor levels in different neurological diseases. Biomed Res Int, 2013:901082.

[43] Kao PF, Banigan MG, Vanderburg CR, McKee AC, Polgar PR, Seshadri S, et al. (2012). Increased expression of TrkB and Capzb2 accompanies preserved cognitive status in early Alzheimer disease pathology. J Neuropathol Exp Neurol, 71(7):654-64.

[44] Scott Bitner R (2012). Cyclic AMP response elementbinding protein (CREB) phosphorylation: a mechanistic marker in the development of memory enhancing Alzheimer's disease therapeutics. Biochem Pharmacol, 83(6):705-14.

[45] Hu YS, Long N, Pigino G, Brady ST, Lazarov O (2013). Molecular mechanisms of environmental enrichment: impairments in Akt/GSK3beta, neurotrophin-3 and CREB signaling. PLoS One, 8(5):e64460.

[46] Chuu JY, Taylor JL, Tinklenberg J, Noda A, Yesavage J, Murphy GM, Jr. (2006). The brain-derived neurotrophic factor Val66Met polymorphism and rate of decline in Alzheimer's disease. J Alzheimers Dis, 9(1):43-9.

[47] Akatsu H, Yamagata HD, Kawamata J, Kamino K, Takeda M, Yamamoto T, et al. (2006). Variations in the BDNF gene in autopsy-confirmed Alzheimer's disease and dementia with Lewy bodies in Japan. Dement Geriatr Cogn Disord, 22(3):216-22.

[48] Nagata T, Kobayashi N, Shinagawa S, Yamada H, Kondo K, Nakayama K (2014). Plasma BDNF levels are correlated with aggressiveness in patients with amnestic mild cognitive impairment or Alzheimer disease. J Neural Transm, 121(4):433-41.

[49] Sonali N, Tripathi M, Sagar R, Vivekanandhan S (2013). Val66Met polymorphism and BDNF levels in Alzheimer's disease patients in North Indian population. Int J Neurosci, 123(6):409-16.

[50] Lim YY, Villemagne VL, Laws SM, Ames D, Pietrzak RH, Ellis KA, et al. (2013). BDNF Val66Met, Abeta amyloid, and cognitive decline in preclinical Alzheimer's disease. Neurobiol Aging, 34(11):2457-64.

[51] Hsiao YH, Hung HC, Chen SH, Gean PW (2014). Social interaction rescues memory deficit in an animal model of Alzheimer's disease by increasing BDNF-dependent hippocampal neurogenesis. J Neurosci, 34(49):1620719.

[52] Shin MK, Kim HG, Baek SH, Jung WR, Park DI, Park JS, et al. (2014). Neuropep-1 ameliorates learning and memory deficits in an Alzheimer's disease mouse model, increases brain-derived neurotrophic factor expression in the brain, and causes reduction of amyloid beta plaques. Neurobiol Aging, 35(5):990-1001.

[53] Han K, Jia N, Li J, Yang L, Min LQ (2013). Chronic caffeine treatment reverses memory impairment and the expression of brain BNDF and TrkB in the PS1/APP double transgenic mouse model of Alzheimer's disease. Mol Med Rep, 8(3):737-40.

[54] Prakash A, Kumar A (2014). Role of nuclear receptor on regulation of BDNF and neuroinflammation in hippocampus of beta-amyloid animal model of Alzheimer's disease. Neurotox Res, 25(4):335-47.

[55] Fukumoto K, Mizoguchi H, Takeuchi H, Horiuchi H, Kawanokuchi J, Jin S, et al. (2014). Fingolimod increases brain-derived neurotrophic factor levels and ameliorates amyloid beta-induced memory impairment. Behav Brain Res, 268:88-93.

[56] Chao MV, Hempstead BL (1995). p75 and Trk: a tworeceptor system. Trends Neurosci, 18(7):321-6.

[57] Esposito D, Patel P, Stephens RM, Perez P, Chao MV, Kaplan DR, et al. (2001). The cytoplasmic and transmembrane domains of the p75 and Trk A receptors regulate high affinity binding to nerve growth factor. $\mathrm{J}$ Biol Chem, 276(35):32687-95.

[58] Nykjaer A, Lee R, Teng KK, Jansen P, Madsen P, Nielsen MS, et al. (2004). Sortilin is essential for 
proNGF-induced neuronal cell death. Nature, 427(6977):843-8.

[59] Fahnestock M, Michalski B, Xu B, Coughlin MD (2001). The precursor pro-nerve growth factor is the predominant form of nerve growth factor in brain and is increased in Alzheimer's disease. Mol Cell Neurosci, 18(2):210-20.

[60] Beattie MS, Harrington AW, Lee R, Kim JY, Boyce SL, Longo FM, et al. (2002). ProNGF induces p75-mediated death of oligodendrocytes following spinal cord injury. Neuron, 36(3):375-86.

[61] Song W, Volosin M, Cragnolini AB, Hempstead BL, Friedman WJ (2010). ProNGF induces PTEN via p75NTR to suppress Trk-mediated survival signaling in brain neurons. J Neurosci, 30(46):15608-15.

[62] Guo J, Wang J, Liang C, Yan J, Wang Y, Liu G, et al. (2013). proNGF inhibits proliferation and oligodendrogenesis of postnatal hippocampal neural stem/progenitor cells through p75NTR in vitro. Stem Cell Res, 11(2):874-87.

[63] Wang YJ, Valadares D, Sun Y, Wang X, Zhong JH, Liu $\mathrm{XH}$, et al. (2010). Effects of proNGF on neuronal viability, neurite growth and amyloid-beta metabolism. Neurotox Res, 17(3):257-67.

[64] Al-Shawi R, Hafner A, Olsen J, Chun S, Raza S, Thrasivoulou C, et al. (2008). Neurotoxic and neurotrophic roles of proNGF and the receptor sortilin in the adult and ageing nervous system. Eur J Neurosci, 27(8):2103-14.

[65] Terry AV, Jr., Kutiyanawalla A, Pillai A (2011). Agedependent alterations in nerve growth factor (NGF)related proteins, sortilin, and learning and memory in rats. Physiol Behav, 102(2):149-57.

[66] Korsching S, Auburger G, Heumann R, Scott J, Thoenen $H$ (1985). Levels of nerve growth factor and its mRNA in the central nervous system of the rat correlate with cholinergic innervation. Embo J, 4(6):1389-93.

[67] Larkfors L, Ebendal T, Whittemore SR, Persson H, Hoffer B, Olson L (1987). Decreased level of nerve growth factor (NGF) and its messenger RNA in the aged rat brain. Brain Res, 427(1):55-60.

[68] Perovic M, Tesic V, Mladenovic Djordjevic A, Smiljanic K, Loncarevic-Vasiljkovic N, Ruzdijic S, et al. (2013). BDNF transcripts, proBDNF and proNGF, in the cortex and hippocampus throughout the life span of the rat. Age, 35(6):2057-70.

[69] Hasenohrl RU, Soderstrom S, Mohammed AH, Ebendal T, Huston JP (1997). Reciprocal changes in expression of mRNA for nerve growth factor and its receptors TrkA and LNGFR in brain of aged rats in relation to maze learning deficits. Exp Brain Res, 114(2):205-13.

[70] Yang C, Liu Y, Ni X, Li N, Zhang B, Fang X (2014). Enhancement of the nonamyloidogenic pathway by exogenous NGF in an Alzheimer transgenic mouse model. Neuropeptides, 48(4):233-8.

[71] Parikh V, Howe WM, Welchko RM, Naughton SX, D'Amore DE, Han DH, et al. (2013). Diminished trkA receptor signaling reveals cholinergic-attentional vulnerability of aging. Eur J Neurosci, 37(2):278-93.
[72] Murase K, Nabeshima T, Robitaille Y, Quirion R, Ogawa M, Hayashi K (1993). NGF level of is not decreased in the serum, brain-spinal fluid, hippocampus, or parietal cortex of individuals with Alzheimer's disease. Biochem Biophys Res Commun, 193(1):198203.

[73] Blasko I, Lederer W, Oberbauer H, Walch T, Kemmler $\mathrm{G}$, Hinterhuber H, et al. (2006). Measurement of thirteen biological markers in CSF of patients with Alzheimer's disease and other dementias. Dement Geriatr Cogn Disord, 21(1):9-15.

[74] Ji C, Song C, Zuo P (2011). The mechanism of memory impairment induced by Abeta chronic administration involves imbalance between cytokines and neurotrophins in the rat hippocampus. Curr Alzheimer Res, 8(4):410-20.

[75] Ferreira D, Westman E, Eyjolfsdottir H, Almqvist P, Lind G, Linderoth B, et al. (2015). Brain changes in Alzheimer's disease patients with implanted encapsulated cells releasing nerve growth factor. J Alzheimers Dis, 43(3):1059-72.

[76] Mufson EJ, He B, Nadeem M, Perez SE, Counts SE, Leurgans S, et al. (2012). Hippocampal proNGF signaling pathways and beta-amyloid levels in mild cognitive impairment and Alzheimer disease. J Neuropathol Exp Neurol, 71(11):1018-29.

[77] Covaceuszach S, Capsoni S, Ugolini G, Spirito F, Vignone D, Cattaneo A (2009). Development of a non invasive NGF-based therapy for Alzheimer's disease. Curr Alzheimer Res, 6(2):158-70.

[78] Hellweg R, Gericke CA, Jendroska K, Hartung HD, Cervos-Navarro J (1998). NGF content in the cerebral cortex of non-demented patients with amyloid-plaques and in symptomatic Alzheimer's disease. Int $\mathrm{J}$ Dev Neurosci, 16(7-8):787-94.

[79] Eriksdotter Jonhagen M, Nordberg A, Amberla K, Backman L, Ebendal T, Meyerson B, et al. (1998). Intracerebroventricular infusion of nerve growth factor in three patients with Alzheimer's disease. Dement Geriatr Cogn Disord, 9(5):246-57.

[80] Mellott TJ, Pender SM, Burke RM, Langley EA, Blusztajn JK (2014). IGF2 ameliorates amyloidosis, increases cholinergic marker expression and raises BMP9 and neurotrophin levels in the hippocampus of the APPswePS1dE9 Alzheimer's disease model mice. PLoS One, 9(4):e94287.

[81] Noh H, Seo H (2014). Age-dependent effects of valproic acid in Alzheimer's disease (AD) mice are associated with nerve growth factor (NGF) regulation. Neuroscience, 266:255-65.

[82] Ari C, Borysov SI, Wu J, Padmanabhan J, Potter H (2014). Alzheimer amyloid beta inhibition of Eg5/kinesin 5 reduces neurotrophin and/or transmitter receptor function. Neurobiol Aging, 35(8):1839-49.

[83] Peng S, Wuu J, Mufson EJ, Fahnestock M (2004). Increased proNGF levels in subjects with mild cognitive impairment and mild Alzheimer disease. J Neuropathol Exp Neurol, 63(6):641-9.

[84] Podlesniy P, Kichev A, Pedraza C, Saurat J, Encinas M, Perez B, et al. (2006). Pro-NGF from Alzheimer's 
disease and normal human brain displays distinctive abilities to induce processing and nuclear translocation of intracellular domain of p75NTR and apoptosis. Am J Pathol, 169(1):119-31.

[85] Pedraza CE, Podlesniy P, Vidal N, Arevalo JC, Lee R, Hempstead B, et al. (2005). Pro-NGF isolated from the human brain affected by Alzheimer's disease induces neuronal apoptosis mediated by p75NTR. Am J Pathol, 166(2):533-43.

[86] Deister C, Schmidt CE (2006). Optimizing neurotrophic factor combinations for neurite outgrowth. J Neural Eng, 3(2):172-9.

[87] Lin LF, Doherty DH, Lile JD, Bektesh S, Collins F (1993). GDNF: a glial cell line-derived neurotrophic factor for midbrain dopaminergic neurons. Science, 260(5111):1130-2.

[88] Trupp M, Arenas E, Fainzilber M, Nilsson AS, Sieber BA, Grigoriou M, et al. (1996). Functional receptor for GDNF encoded by the c-ret proto-oncogene. Nature, 381(6585):785-9.

[89] Baloh RH, Tansey MG, Golden JP, Creedon DJ, Heuckeroth RO, Keck CL, et al. (1997). TrnR2, a novel receptor that mediates neurturin and GDNF signaling through Ret. Neuron, 18(5):793-802.

[90] Jankovic J (2008). Parkinson's disease: clinical features and diagnosis. J Neurol Neurosurg Psychiatry, 79(4):368-76.

[91] Pertusa M, Garcia-Matas S, Mammeri H, Adell A, Rodrigo T, Mallet J, et al. (2008). Expression of GDNF transgene in astrocytes improves cognitive deficits in aged rats. Neurobiol Aging, 29(9):1366-79.

[92] Allen SJ, Watson JJ, Shoemark DK, Barua NU, Patel NK (2013). GDNF, NGF and BDNF as therapeutic options for neurodegeneration. Pharmacol Ther, 138(2):155-75.

[93] Gill SS, Patel NK, Hotton GR, O'Sullivan K, McCarter R, Bunnage M, et al. (2003). Direct brain infusion of glial cell line-derived neurotrophic factor in Parkinson disease. Nat Med, 9(5):589-95.

[94] Slevin JT, Gerhardt GA, Smith CD, Gash DM, Kryscio $\mathrm{R}$, Young B (2005). Improvement of bilateral motor functions in patients with Parkinson disease through the unilateral intraputaminal infusion of glial cell linederived neurotrophic factor. J Neurosurg, 102(2):216-22.

[95] Farrand AQ, Gregory RA, Scofield MD, Helke KL, Boger HA (2015). Effects of aging on glutamate neurotransmission in the substantia nigra of Gdnf heterozygous mice. Neurobiol Aging, 36(3):1569-76.

[96] Matsunaga W, Isobe K, Shirokawa T (2006). Involvement of neurotrophic factors in aging of noradrenergic innervations in hippocampus and frontal cortex. Neurosci Res, 54(4):313-8.

[97] Zurn AD, Winkel L, Menoud A, Djabali K, Aebischer P (1996). Combined effects of GDNF, BDNF, and CNTF on motoneuron differentiation in vitro. J Neurosci Res, 44(2):133-41.

[98] Zurn AD, Baetge EE, Hammang JP, Tan SA, Aebischer $P$ (1994). Glial cell line-derived neurotrophic factor
(GDNF), a new neurotrophic factor for motoneurones. Neuroreport, 6(1):113-8.

[99] Arenas E, Trupp M, Akerud P, Ibanez CF (1995). GDNF prevents degeneration and promotes the phenotype of brain noradrenergic neurons in vivo. Neuron, 15(6):1465-73.

[100] Chao CC, Lee EH (1999). Neuroprotective mechanism of glial cell line-derived neurotrophic factor on dopamine neurons: role of antioxidation. Neuropharmacology, 38(6):913-6.

[101] Cheng H, Fu YS, Guo JW (2004). Ability of GDNF to diminish free radical production leads to protection against kainate-induced excitotoxicity in hippocampus. Hippocampus, 14(1):77-86.

[102] Fox CM, Gash DM, Smoot MK, Cass WA (2001). Neuroprotective effects of GDNF against 6-OHDA in young and aged rats. Brain Res, 896(1-2):56-63.

[103] McCullough MJ, Gyorkos AM, Spitsbergen JM (2013). Short-term exercise increases GDNF protein levels in the spinal cord of young and old rats. Neuroscience, 240(0):258-68.

[104] Ghribi O, Herman MM, Forbes MS, DeWitt DA, Savory J (2001). GDNF protects against aluminum-induced apoptosis in rabbits by upregulating Bcl-2 and Bcl-XL and inhibiting mitochondrial Bax translocation. Neurobiol Dis, 8(5):764-73.

[105] Straten G, Saur R, Laske C, Gasser T, Annas P, Basun $\mathrm{H}$, et al. (2011). Influence of lithium treatment on GDNF serum and CSF concentrations in patients with early Alzheimer's disease. Curr Alzheimer Res, 8(8):853-9.

[106] Marksteiner J, Kemmler G, Weiss EM, Knaus G, Ullrich C, Mechtcheriakov S, et al. (2011). Five out of 16 plasma signaling proteins are enhanced in plasma of patients with mild cognitive impairment and Alzheimer's disease. Neurobiol Aging, 32(3):539-40.

[107] Airavaara M, Pletnikova O, Doyle ME, Zhang YE, Troncoso JC, Liu QR (2011). Identification of novel GDNF isoforms and cis-antisense GDNFOS gene and their regulation in human middle temporal gyrus of Alzheimer disease. J Biol Chem, 286(52):45093-102.

[108] Forlenza OV, Teixeira AL, Miranda AS, Barbosa IG, Talib LL, Diniz BS, et al. (2015). Decreased Neurotrophic Support is Associated with Cognitive Decline in Non-Demented Subjects. J Alzheimers Dis, 3:3.

[109] Revilla S, Sunol C, Garcia-Mesa Y, Gimenez-Llort L, Sanfeliu C, Cristofol R (2014). Physical exercise improves synaptic dysfunction and recovers the loss of survival factors in $3 \times \mathrm{Tg}-\mathrm{AD}$ mouse brain. Neuropharmacology, 81:55-63.

[110] Revilla S, Ursulet S, Alvarez-Lopez MJ, Castro-Freire M, Perpina U, Garcia-Mesa Y, et al. (2014). LentiGDNF gene therapy protects against Alzheimer's disease-like neuropathology in 3xTg-AD mice and MC65 cells. CNS Neurosci Ther, 20(11):961-72. 